\title{
Assura darf Doppeltitelträger nicht ausschliessen
}

\author{
Hanspeter Kuhn \\ Fürsprecher, Leiter FMH-Rechtsdienst
}

Die Krankenkasse Assura betreibt ein Versicherungsmodell mit eingeschränkter Wahl des Leistungserbringers, ein sogenanntes Hausarztmodell. Sie schloss seit 1. Januar 2012 Doppeltitelträger kategorisch von diesem Modell aus. Ein Facharzt für Allgemeine Innere Medizin und für Allergologie und Immunologie aus dem Kanton Neuenburg hat gegen diesen Ausschluss geklagt. Er hat vor dem kantonalen Schiedsgericht und nun auch vor dem Bundesgericht Recht bekommen.

\section{Aus dem Urteil}

Der Krankenversicherer nimmt auch beim Angebot von besonderen Versicherungsformen eine Bundesaufgabe wahr und untersteht dem öffentlichen Recht. Auch im Managed-Care-Bereich gilt für ihn deshalb gegenüber dem Arzt Art. 35 Abs. 2 der Bundesverfassung: «Wer staatliche Aufgaben wahrnimmt, ist an die Grundrechte gebunden und verpflichtet, zu ihrer Verwirklichung beizutragen.» (E. 5)

Die obligatorische soziale Krankenversicherung muss sicherstellen, «dass eine allfällige Zugangsregelung nur nach sachlich haltbaren, den Grundsätzen des Wettbewerbs unter Konkurrenten sachgerecht Rechnung tragenden Kriterien erfolgt» (das Bundesgericht übernimmt hier seine Erwägungen aus dem Entscheid von 2003 zum Zulassungsstopp).

Nach dem Grundsatz der Gleichbehandlung der Gewerbegenossen sind Massnahmen verboten, die den Wettbewerb unter direkten Konkurrenten verzerren bzw. nicht wettbewerbsneutral sind [...]. Die Gleichbehandlung der Gewerbegenossen geht gemäss dem vom Bundesgericht zitierten BGE 125 I 431 zu den Ladenöffnungszeiten in Zürich weiter als das allgemeine Rechtsgleichheitsgebot: Sie gewährt einen Schutz vor staatlichen Ungleichbehandlungen, die [...] einzelne Konkurrenten namentlich durch unterschiedliche Belastungen oder staatlich geregelten Marktzugang bzw. -ausschluss begünstigen oder benachteiligen (E. 7.2).

Die Auswahl von Ärztinnen und Ärzten für eine sogenannte Hausärzteliste darf ausschliesslich «im Hinblick auf eine kostengünstigere Versorgung» erfolgen. Das Bundesgericht hat die kategorische Behauptung der Assura zurückgewiesen, Doppeltitelträger würden teurer arbeiten. Der Versicherer muss diesen Nachweis im Einzelfall konkret führen. Der Assura ist es nicht gelungen zu beweisen, dass der klagende Doppeltitelträger teurer arbeitet als seine Gewerbegenossen. Seine Nichtaufnahme auf die Hausärzteliste verstiess damit gegen das Willkürverbot, die Rechtsgleichheit und die Gleichbehandlung der Gewerbegenossen (E. 9).

\section{Kommentar}

Das Bundesgericht hat mit diesem wichtigen Grundsatzentscheid Klarheit geschaffen. Der Versicherer muss auch im Managed-Care-Bereich die Grundrechte der Ärztinnen und Ärzte respektieren. Seine Auswahlkriterien für Hausärztelisten müssen objektiv sein und im Einzelfall nachgewiesen werden. Kategorische Ausschlüsse sind unzulässig.

Der FMH-Rechtsdienst hatte die Assura schon 2011 gewarnt: «Der Krankenversicherer, der Hausarztmodelle anbietet, [...] handelt als mittelbare Staatsverwaltung und ist in seinem Vorgehen nicht mehr frei, sondern muss sich den Grundsätzen unterziehen, die für die Verwaltung gelten. Dazu zählen insbesondere das Willkürverbot und das Gebot rechtsgleicher Behandlung. KVG Art. 41 Abs. 4 macht allein die kostengünstigere Versorgung zum Kriterium: 'Die Versicherten können ihr Wahlrecht im Einvernehmen mit dem Versicherer auf Leistungserbringer beschränken, die der Versicherer im Hinblick auf eine kostengünstigere Versorgung auswählt (Art. 62 Abs. 1 und 3).' Der Versicherer muss Patienten und Ärzte rechtsgleich behandeln. Das heisst: Wenn er in derselben Ortschaft den Internisten A auf die Liste nimmt, nicht aber die Internistin und Rheumato$\operatorname{login} B$, muss er belegen können, dass B vergleichbare Patienten teurer behandelt als A» [2].

Das Bundesgericht hat diese Überlegungen nun vollumfänglich bestätigt, was die FMH mit Genugtuung zur Kenntnis nimmt. Seit dem Ausschluss der Doppeltitelträger von den Hausarztmodellen der Assura im Jahr 2012 hat sich die FMH durch Rechtsberatung der betroffenen Ärztinnen und Ärzte wie 2013 durch das Angebot finanzieller Prozessunterstützung in geeigneten Fällen dafür engagiert, diesen Missstand zu beheben. Zudem setzte sie sich im Jahr 2014 im Parlament gemeinsam mit der Société Vaudoise de Médecine für die Annahme der Parlamentarischen Initiative 13.433 «Keine Benachteiligung von Fachärzten für Allgemeine Innere Medizin mit einem zweiten Facharzttitel» ein. Erfreulicherweise hat das Bundesgericht nun aufgrund des geltenden Gesetzes Klartext gesprochen. 